ББК 63.4

$$
\begin{gathered}
\text { Организация конференции и издание материалов проведены } \\
\text { при финансовой поддержке Российского фонда фундаментальных исследований, } \\
\text { проект № 19-09-20008 }
\end{gathered}
$$

Утверждено к печати Ученым советом ИИМК РАН

Редакционная коллегия тома II: А. В. Поляков, Е. С. Ткач (отв. редакторы), М. Т. Кашуба, Л. Б. Кирчо, Е. А. Черлёнок, В. Я. Стёганцева, А. И. Климушина

Рещензенты: д. и. н. Л. Б. Вишняцкий, д. и. н. А. А. Выборнов

Программный комитет конференции: академик РАН, д. и. н., проф. М. Б. Пиотровский (Государственный Эрмитаж, почетный председатель); д. и. н. В. А. Лапшин (ИИМК РАН, председатель); д. и. н. А. В. Головнёв (МАЭ РАН, сопредседатель); д. и. н. В. А. Дергачёв (Высшая антропологическая школа, Молдова, сопредседатель); д. и. н. И. Ф. Попова (ИВР РАН, сопредседатель); академик АН Республики Узбекистан, д. и. н., проф. Э. В. Ртвеладзе (сопредседатель); к. и. н. А. В. Поляков (ИИМК РАН, зам. председателя); к. и. н. В. А. Алёкшин (ИИМК РАН, зам. председателя); д. и. н. Ю. Е. Берёзкин (МАЭ РАН); Dr., Prof. Н. Бороффка

(Германский археологический институт, Германия); В. С. Бочкарёв (ИИМК РАН);

Dr. Э. Кайзер (Свободный университет Берлина, Германия); к. и. н. М. Т. Кашуба (ИИМК РАН); д. и. н. Л. Б. Кирчо (ИИМК РАН); к. и. н. А. В. Кияшко (Южный федеральный университет); к. и. н. П. Ф. Кузнецов (СГСПУ); к. и. н. Н. М. Малов (СНИГУ); к. и. н. В. П. Никоноров (ИИМК РАН); Ю. Ю. Пиотровский (Государственный Эрмитаж); д. и. н., проф. Д. Г. Савинов (Институт истории СПбГУ); к. и. н. В. Н. Седых (Институт истории СПбГУ); к. и. н. Н. Н. Скакун (ИИМК РАН); к. и. н. Н. Ф. Соловьёва (ИИМК РАН); к. и. н. А. И. Торгоев (Государственный Эрмитаж); к. и. н. Е. А. Черлёнок (Институт истории СПбГУ)

Организационный комитет конференции: к. и. н. А. В. Поляков (ИИМК РАН, председатель); к. и. н. В. А. Алёкшин (ИИМК РАН, зам. председателя); В. С. Бочкарёв (ИИМК РАН); к. и. н. М. Т. Кашуба (ИИМК РАН); д. и. н. Л. Б. Кирчо (ИИМК РАН);

А. И. Климушина (ИИМК РАН, отв. секретарь); к. и. н. В. П. Никоноров (ИИМК РАН); Ю. Ю. Пиотровский (Государственный Эрмитаж); В. Я. Стеганцева (ИИМК РАН); В. В. Терёхина (ИИМК РАН, МАЭ РАН, отв. секретарь); к. и. н. Е. С. Ткач (ИИМК РАН); И. Ж. Тутаева (Государственный Эрмитаж); к. и. н. Е. А. Черлёнок (Институт истории СПбГУ)

Древности Восточной Европы, Центральной Азии и Южной Сибири в контексте связей и взаимодействий в евразийском культурном пространстве (новые данные и концепции): Материалы Международной конференции, 18-22 ноября 2019 г., Санкт-Петербург. Т. ІІ. Связи, контакты и взаимодействия древних культур Северной Евразии и цивилизаций Востока в эпоху палеометалла (IV-I тыс. до н. э.). К 80-летию со дня рождения выдающегося археолога В. С. Бочкарёва. - СПб.: ИИМК РАН, Невская Типография, 2019. - 287 с.

ISBN 978-5-907053-35-9

DOI 10.31600/978-5-907053-35-9 
растиральниками. Единичны навершие булавы из ракушечника и обломок проушного топора-молота. Кремневые орудия малочисленны, в основном это вкладыши серпов и скребки. Изделия из кости представлены проколками, рукоятями орудий, шлифованными астрагалами, «коньками» из метаподий лошади, «тупиками» из нижних ветвей челюсти лошади и стругами из ребер коровы. Металлические изделия немногочисленны три бронзовых шила и листовидный нож раннесабатиновского времени.

Полученные материалы имеют сходство с материалами памятников сабатиновско-белозерского круга. Ближайшие аналогии полученным материалам обнаруживаются на поселениях Балка Лисовицкого 4 (Таманский п-ов) и Луговое Северо-западное (Крым).

\title{
NEW EVIDENCE ON THE SETTLEMENT OF PANAGIYA 1 OF THE LATE BRONZE AGE ON THE TAMAN PENINSULA (MATERIALS FROM EXCAVATIONS OF 2019)
}

\author{
Andrey A. Goroshnikov, Zoya V. Goroshnikova
}

Ltd "Kubanarcheology", Krasnodar, Russia

Keywords: Taman Peninsula, settlement of Panagiya 1, Late Bronze Age.

This study is devoted to the results of archaeological excavations of 2019 at an area of the Late Bronze Age settlement of Panagiya 1 situated in the south-western part of the Taman Peninsula. The investigation of the site was started in 2018; its southern part was excavated over the area of 3.34 ha. In the investigated territory, there were discovered numerous archaeological objects both of a dwelling and burial types.

In 2019, the investigation of the site was continued and, now, its central part was the subject of the excavations. In the area investigated, like in the excavation of 2018, various objects were discovered vividly characterizing the material culture of the population of the Taman Peninsula in the Late Bronze Age. The materials obtained show similarity with those of the Sabatinovka-Belozerka circle of cultures.

\section{НЕКОТОРЫЕ РЕЗУЛЬТАТЫ ИССЛЕДОВАНИЙ НА ПОСЕЛЕНИЯХ КОМПЛЕКСА КУЛЬТУР НОУА-САБАТИНОВКА- КОСЛОЖЕНЬ, РАСПОЛОЖЕННЫХ В ЮЖНОЙ ЧАСТИ РЕСПУБЛИКИ МОЛДОВА}

Е. Сава ${ }^{\star}$, Э. Кайзер ${ }^{* *}$, М. Сырбу

${ }^{*}$ Национальный музей истории Молдовы, Кишинёв, Молдова; ${ }^{*}$ Свободный университет, Институт доисторической археологии, Берлин, Германия

DOI: 10.31600/978-5-907053-35-9-169-171

Ключевые слова: поздний бронзовый век, поселения, «зольники», комплекс культур НоуаСабатиновка-Косложень, Буджакская степь.

В позднем бронзовом веке на огромной территории (от Восточной Трансильвании на западе до Нижнего Поднепровья на востоке, от Верхнего Поднестровья на севере до Нижнего Подунавья на юге) сформировалась группа археологических культур, известная как комплекс культур Ноуа-Сабатиновка-Косложень. Одним из основных диагностических элементов поселений этого комплекса культур являются «зольники», функциональность и значение которых длительное время являются предметом дискуссий.

На одном из поселений культуры Ноуа (Одая-Мичурин) в 2003-2008 гг. проведены комплексные археологические и междисциплинарные исследования. Исходя из результатов 
раскопок поселения культуры Ноуа Одая-Мичурин и других поселений в лесостепной части Пруто-Днестровского междуречья, можно сделать вывод, что во всем ареале культуры Ноуа наиболее типичными являются только два типа жилищ - углубленные и наземные постройки, которые, вероятно, сооружались из жердей и глины. Практически ни в одном «зольнике» культуры Ноуа не были обнаружены каменные конструкции, аналогичные тем, которые часто встречаются на поселениях сабатиновской культуры.

Однако, с нашей точки зрения, верхняя часть стен каменных построек, типичных для поселений сабатиновской культуры, также состояла из деревянных каркасов, обмазанных глиной, или же они были покрыты органическими материалами - соломой, камышом и пр. Для проверки этого тезиса разработана концепция и осуществляется проект комплексных археологических и междисциплинарных исследований поселений культуры Сабатиновка, расположенных в степной зоне Пруто-Поднестровья.

Для изучения выбрана самая южная, наименее исследованная часть Пруто-Днестровского региона - Буджакская степь. В регионе известны более 20 поселений сабатиновской культуры, однако ни на одном из них, проверенных разведками, визуально не обнаружены «зольники». Однако на этих поселениях собраны многочисленные фрагменты керамики, орудия из камня и кости, явно относящиеся к сабатиновской культуре. В 2016-2018 гг. некоторые поселения были раскопаны.

На поселении Казаклия II во время разведки в 2016 г. на вспаханном участке обнаружены и собраны более 30 фрагментов крупного сосуда типа пифос, сконцентрированных на площади около 1,5 м². Там же зафиксирован круглый контур ямы, имевшей глубину не более 0,4 м от уровня современной дневной поверхности. В заполнении ямы, от уровня обнаружения и до самого дна, вперемешку находились более 600 фрагментов как минимум от 10 глиняных сосудов разного размера, при этом преобладали фрагменты от крупных сосудов типа пифос.

На поселении Тараклия-Гайдабул в 2017-2018 гг. проведены стационарные раскопки.

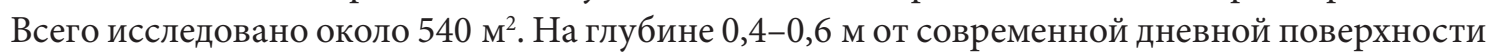
зафиксированы разбросанные камни различной величины, которые по мере снятия грунта на некоторых участках образовывали более четкие очертания и, видимо, являются остатками каменных сооружений. На этой площади начиная с глубины 1 м от современной дневной поверхности стал проявляться контур «зольника» в виде неправильной овальной фигуры диаметром более 30 м. Диаметр «зольника» по мере снятия раскопочных слоев и углубления изменялся в сторону увеличения.

На вскрытой площади обнаружены многочисленные фрагменты керамики, в том числе от сосудов типа пифос, изделия из кости, камня и, редко, из бронзы. По всей площади зафиксированы 30 ям, в которых находились многочисленные кости животных: иногда части скелета крупного рогатого скота, лошадей, а также три полностью сохранившихся скелета собак. Большинство ям в древности были перекрыты крупными камнями.

По палеозоологическим определениям состав фаунистический коллекции поселения Тараклия-Гайдабул следующий: крупный рогатый скот $-51 \%$; овца-коза $-25 \%$; лошадь - $20 \%$; собака $-2 \%$; свинья $-1 \%$, дикие животные $-1 \%$.

Кроме многочисленных костей животных на раскопанной площади обнаружено более 40 фрагментов костей человека от семи индивидов. Кроме того на исследуемой площади памятника обнаружены три сарматских погребения, что возможно указывает на наличие в данном месте грунтового могильника этого времени.

11 проб, отобранных для радиоуглеродных определений, показали, что поселение сабатиновской культуры Тараклия-Гайдабул может быть датировано XVI-XI вв. до н. э. 


\title{
SEVERAL RESULTS OF ARCHAEOLOGICAL INVESTIGATIONS \\ OF SETTLEMENTS IN THE SOUTHERN PART OF THE REPUBLIC OF MOLDOVA DATING TO THE NOUA-SABATINOVKA-COSLOGENI CULTURAL COMPLEX
}

\author{
Eugen Sava*, Elke Kaiser ${ }^{\star *}$, Mariana Syrbu ${ }^{*}$ \\ ${ }^{\star}$ National museum of the History in Moldova, Chişinău, Moldova; ${ }^{* *}$ Freie Universität Berlin, \\ Institute of Prehistory, Berlin, Germany
}

Keywords: Late Bronze Age, settlements, ash deposits, Noua-Sabatinovka-Coslogeni cultural complex, Budzhak steppe.

Complex archaeological and multidisciplinary investigations carried out between 2003 and 2008 at the Odaia-Miciurin settlement of the Noua culture have enabled the researchers to develop a model describing the formation and functions of the so-called "ash deposits". Through this model, it is also possible to understand the system of subsistence economy of the Noua culture. Since no comparative research has as yet been undertaken for settlements of the Sabatinovka culture, an archaeological and multidisciplinary project has been designed for the Late Bronze Age settlements located in the south of the Republic of Moldova. In our paper we will present the preliminary results of the project obtained in 2016-2018.

\section{«БОГАТЫЕ» ПОГРЕБЕНИЯ ПОЗДНЯКОВСКОЙ КУЛЬТУРЫ: СВЯЗИ, ХРОНОЛОГИЯ И ЗНАЧЕНИЕ}

\author{
Е. С. Азаров \\ Государственный исторический музей, Москва, Россия
}

DOI: 10.31600/978-5-907053-35-9-171-173

Ключевые слова: поздняковская культура, покровская культура, срубная культура, инвентарь, погребение, лесная зона, окский бассейн.

Поздняковская культура - одна из археологических культур Волго-Окского междуречья бронзового века, окончательно выделенная к 1970-м гг. (Попова 1970; Бадер, Попова 1987). Ведущая роль в ее сложении принадлежит срубной культуре с участием местной подосновы. Отмечались аналогии по металлическим вещам в абашевской и андроновской культурах. Выделение культуры сопровождалось критикой в отнесении к ней по сути всех древностей позднего бронзового века Волго-Очья (Никитин 1976: 74), а также некоторых древностей раннего железного века (Кузьминых, Чижевский 2006). Общую непростую ситуацию дополняют и особенности топографического расположения памятников в песчаных грунтах, что отрицательно влияет как на стратиграфию поселений, так и на сохранность органики. При таких условиях наибольшее значение приобретает изучение закрытых комплексов погребальных памятников и особенно тех погребений, которые на фоне общей скупости и маловыразительности погребального инвентаря представлены относительно ярко и могут быть условно отнесены к «богатым» погребениям элиты того времени.

Погребальные памятники поздняковской культуры представлены как курганными, так и грунтовыми могильниками. На сегодняшний день известно около 84 исследованных насыпей семи могильников (Малоокуловский, Коренецкий, Берёзовый рог и ниже указанные), которые содержали чуть более 150 погребений. Из этого числа к «богатым» можно отнести лишь девять комплексов: погребения кург. 1, 3(2?), 8 Борисоглебского могильника (Попова 1967); погр. 4 кург. 1, погр. 2 кург. 2, погр. 1 и 7 кург. 3 и погр. 6 кург. 4 Засеченского могильника (Челяпов 1992); погр. 1 кург. 3 могильника Лебяжий Бор (Челяпов 1995). 